\title{
Effect of Skin Lipid Barrier Formation on Hataedock Treatment with Douchi
}

\author{
Hee-Yeon Kim ${ }^{1,4}$, Sang-hyun $\mathrm{Ahn}^{2}$, Injun Yang ${ }^{3}$, Kibong Kim ${ }^{1,4}$ \\ ${ }^{1}$ Department of Korean Pediatrics, Korean Medicine Hospital, Pusan National University \\ ${ }^{2}$ Department of Anatomy, College of Korean Medicine, Semyung University \\ ${ }^{3}$ Department of Physiology, College of Korean Medicine, Dongguk University \\ ${ }^{4}$ Department of Korean Pediatrics, School of Korean Medicine, Pusan National University
}

\begin{abstract}
Objectives: Hataedock is indigenous treatment of Korean medicine that administers herbal extracts orally to newborn infants for remove the fetal heat. The purpose of this study was to evaluate skin lipid barrier formation effect of Hataedock treatment with Douchi.

Methods: We measured the Western blot to observe the expression of protein such as involucrin and loricrin. Moreover, we observed immunohistochemical changes in NC/Nga mice. The 3-week-old NC/Nga mice were divided into 3 groups: the 3-week-old control group (3w-Ctrl), 5-week-old control group (5w-Ctrl), and the Hataedock-treated group (5w-FGT). Only the $5 \mathrm{w}-\mathrm{FGT}$ group was treated with Douchi at the 3rd week. We identified the changes of the lipid skin barrier and protein differentiation through immunohistochemical changes of involucrin, loricrin, filaggrin and acid sphingomyelinase (ASM) in the stratum corneum.

Results: The expression of involucrin and loricrin was increased in the Western blot that was treated with concentration of Douchi extracts. In 5w-FGT group, loricrin-positive reaction was increased by $54.0 \%$, involucrin-positive reaction was increased by $84.0 \%$, filaggrin-positive reaction was increased by $108.0 \%$ and ASM-positive reaction was increased by $91.0 \%$ in the stratum corneum.

Conclusions: These results suggest that Hataedock treatment with Douchi promoted skin lipid barrier formation by promoting differentiation of keratinocytes.
\end{abstract}

$\overline{K e y}$ Words : Hataedock, Douchi(豆豉), filaggrin, loricrin, involucrin

\section{Introduction}

The epidermis is the skin barrier that keeps moisture in the body and has the primary barrier function and immune response to external invading factors such as antigen and infectious agent ${ }^{1,2)}$. The barrier function of the epidermis occurs through the stratum corneum structure consisting of corneocyte, cornified envelope, lamellar membrane lipid, intercorneocyte lipid, and corneodesmosome ${ }^{3)}$. In the cornified envelope, the cornified protein envelope is formed by protein cross-linking such as involucrin, loricrin, trichohyalin, and small proline-rich proteins, and serves as a physical barrier ${ }^{4,5}$. The cornified lipid envelope, serves as a scaffold to induce the formation of multilamellar structures of intercellular lipid bilayer, forms a complete skin barrier structure ${ }^{6}$. In addition, filaggrin, one of the important proteins

\footnotetext{
- Received : 26 May 2017

- Revised : 21 June 2017

- Accepted : 21 June 2017

- Correspondence to : Kibong Kim

Department of Korean Pediatrics, Korean Medicine Hospital, Pusan National University

Geumo-ro 20, Mulgeum-eup, Yangsan-si, Gyeongsangnam-do, 50612, Republic of Korea

Te : +82-55-360-5952, Fax : +82-55-360-5952, E-mail : kkb2630@gmail.com
} 
that play an important role in connecting cornified envelope and keratin intermediate microfibers, contributes to the strong physical support of the skin barrier result from acts as not only binds keratin fibers firmly but also contributes to binding proteins such as involucrin and loricrin ${ }^{7}$.

Impairment of skin barrier function correlates with inflammatory skin disease induction. Recently, reports that IL-4, IL-13 and IL-31, which are Th2 differentiation-related cytokines in atopic dermatitis, decreased the expression of proteins such as involucrin, loricrin, and filaggrin that major constituents of the skin barrier ${ }^{8)}$, there is a relationship with atopic dermatitis and filaggrin gene mutation ${ }^{9-12)}$, and atopic dermatitis is alleviated through improvement of skin barrier due to increased expression of filaggrin ${ }^{13)}$. It could be suggested as a basis that treatment system of atopic dermatitis be diverted from based on the inhibition of Th2 skewed condition and anti -inflammation to preventive treatment system based on the improvement of skin barrier.

Hataedock is indigenous treatment of Korean medicine that administers herbal extracts orally to newborn infants for remove the fetal heat ${ }^{14)}$. In Donguibogam(東醫寶鑑), when an infant is born, it is said that soft silk is immersed in a herb medicine, and then wipe away the dirt in the mouth and feed a small amount ${ }^{15}$. Among them Douchi (fermented Glycine $\max$ Merr.) is an herbal medicine that can radiate the heat of the body for reducing heat. Recently it has been reported that the isoflavone component of soybean plants alleviates inflammatory symptoms of the skin caused by heat ${ }^{16,17)}$. In particular, 7, 3', 4'-Trihydroxyisoflavone, a major metabolite of daidzein and genistein, has been reported to maintain the homeostasis of the skin barrier by increasing the expression of filaggrin in $\mathrm{NC} / \mathrm{Nga}$ mice induced atopic dermatitis ${ }^{13)}$.

Previous studies have shown that atopic dermatitis can be controlled after Hataedock treatment with Douchi. Excessive Th2 differentiation caused by increased IL-4 production did not occur in the $\mathrm{NC} / \mathrm{Nga}$ mice treated with Hataedock. Also there were few tissue damage induced by inflammatory cytokine such as iNOS and COX-2, and few edema and itching induced by mast cell activity. It was remarkable results that the maintenance of the stratum corneum of the skin and the resulting less protein kinase $\mathrm{C}$ (PKC) activity ${ }^{18)}$. These results could be assumed that Hataedock treatment controls the induction of atopic dermatitis by inducing the formation of the lipid barrier of the skin. However, there is no evidence on the relationship between atopic dermatitis and changes of skin barrier after Hataedock treatment.

In order to confirm the effect of the skin lipid barrier formation after the Hataedock treatment with Douchi, we observed the immunohistochemical changes of involucrin, loricrin, filaggrin, and acid sphingomyelinase (ASM). In addition, the production of cornified protein envelope such as involucrin and loricrin in the keratinocyte was confirmed by the cell line experiment. We report the significant results in promoting skin lipid barrier formation.

\section{Method and Materials}

\section{Preparation and analysis of Douchi extracts}

The procedure used to manufacture the herb extract for Hataedock treatment was as follows: 100 $\mathrm{g}$ of crushed Douchi (fermented Glycine max Merr, Namyoung Pharm., Muju, Republic of Korea) was decocted with $1000 \mathrm{ml}$ of distilled water for $3 \mathrm{~h}$ and then filtered. The filtrate was concentrated to $50 \mathrm{ml}$ under reduced pressure using a rotary evaporator, and then freeze-dried to obtain $15 \mathrm{~g}$ of the extract (yield: 15.0\%).

The isoflavone components of the Douchi used in this experiment were identified by HPLC and daidzein and genistein were detected (Fig. 1). 


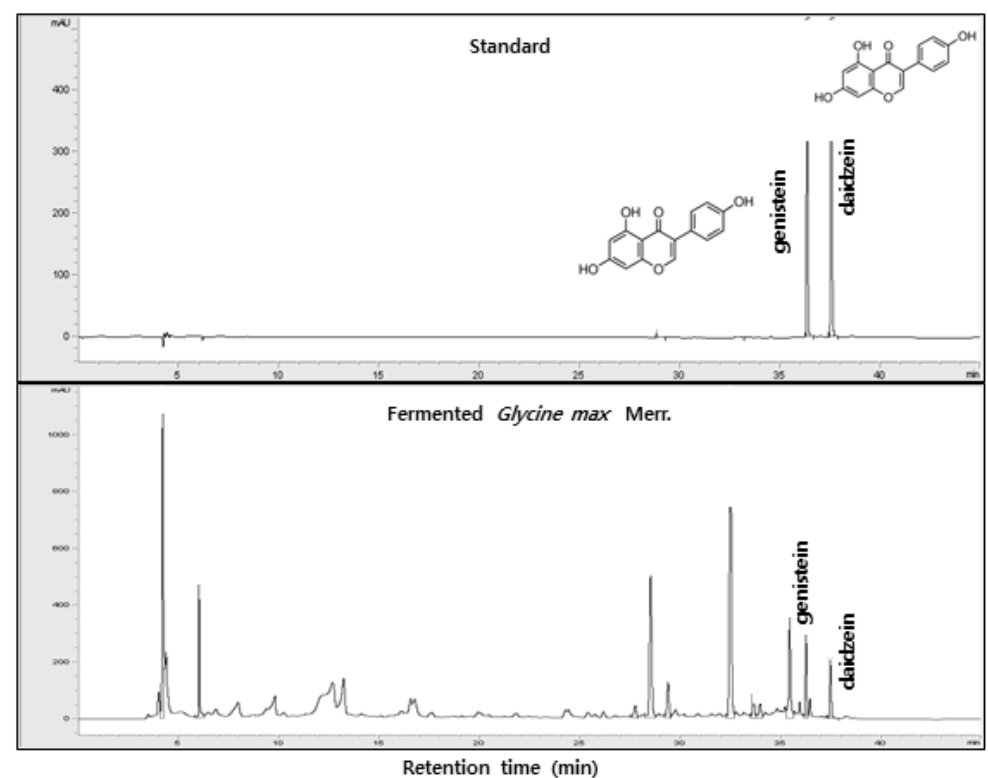

Fig. 1. The representative chromatograms of isovlavones as daidzein \& genistein in fermented Glycine max Merr.

\section{Western blot analysis}

$\mathrm{HaCaT}$ keratinocytes as human keratinocyte were dispensed into the 6-well plate as $4 \times 105$ cells / well, cultured in $80 \%$ confluence, and then cultured for $24 \mathrm{~h}$ after treated with reagents. After culture, the lysate was prepared by treating with RIPA buffer (Atto, Tokyo, Japan), and centrifuged at 12,000 rpm at $4^{\circ} \mathrm{C}$ for $10 \mathrm{~min}$ to recover the supernatant. After protein quantification was performed using the Bradford protein assay reagent, 50ug of proteins were separated by SDS-polyacrylamide gel $(10 \%)$ and transferred to a polyvinylidenedifluoride (PVDF) membrane at $190 \mathrm{~mA}$ for $80 \mathrm{~min}$. The membrane was blocked in PBS containing 5\% skim milk for 1 $\mathrm{h}$ at $37^{\circ} \mathrm{C}$ and treated overnight with an anti-Lorcrin antibody and anti-Involucrin antibody (\# ab24722, \# ab53112, Cambridge, MA, USA). In addition, it was treated with HRP-conjugated anti-rabbit antibody at room temperature for $1 \mathrm{~h}$. After completion of the reaction, the membrane was developed using an enhanced chemiluminescence system (Bio Rad
Laboratories, Hercules, USA) and observed for protein expression on X-ray film.

\section{Hataedock treatment with Douchi}

Male 3-week-old $\mathrm{Nc} / \mathrm{Nga}$ mice (13-15g) were obtained from Central Lab Animal Inc. (Seoul, Republic of Korea). The mice divided into three groups ( $\mathrm{n}=10$ per group) as follows: the 3 -week-old control group ( $3 \mathrm{w}-\mathrm{Ctrl})$, 5-week-old control group (5w-Ctrl), and the Hataedock-treated group (5w-FGT). Hataedock-treated group was orally administered with $10 \mathrm{mg} / \mathrm{kg}$ of Douchi extracts. All procedures were conducted in accordance with IACUC approval (IACUC number: PNU-2015-0924) of Pusan National University and we followed the NIH guidelines for the care and use of laboratory animals.

\section{Tissue slice and Immunohistochemistry}

After 2 weeks of Hataedock treatment, sodium pentobarbital was used to anesthetize mice. Dorsal 
skin was fixed in $10 \%$ neutral buffered formalin (NBF) solution at room temperature for $24 \mathrm{~h}$. The fixed dorsal tissue slices were embedded in paraffin, after then obtained the $5 \mu \mathrm{m}$ thick sections. The skin slices were stepped in proteinase K solution $(20 \mu \mathrm{g} /$ $\mathrm{m}$ ) ) to undergo proteolysis procedure for $5 \mathrm{~min}$, and then were incubated in blocking serum $(10 \%$ normal mouse serum) for $2 \mathrm{~h}$. The slices were incubated with rabbit anti-Loricrin (1:50, Santa Cruz Biotec, USA), rabbit anti-Involucrin (1:50, Santa Cruz Biotec), rabbit anti-Filaggrin (1:100, Santa Cruz Biotec), rabbit anti-ASM (1:50, Santa Cruz Biotec), which are primary antibody, at $4^{\circ} \mathrm{C}$ humidified chamber for $72 \mathrm{~h}$. Next the slices were linked with biotinylated mouse anti-rabbit $\operatorname{IgG}(1: 100$, Santa Cruz Biotec), which is a secondary antibody, for $24 \mathrm{~h}$ at room temperature. After the slices were exposed to the secondary antibody, an avidin biotin complex kit (Vector Lab, USA) was reacted for $1 \mathrm{~h}$ at room temperature. Finally, the slices were developed with $0.05 \mathrm{M}$ tris- $\mathrm{HCl}$ buffer solution $(\mathrm{pH} 7.4)$, which included with $0.05 \% 3$, 3'-diaminobenzidine and $0.01 \% \mathrm{HCl}$, and then contrast-stained with hematoxylin.

\section{Image analysis and statistical analysis}

To quantify our Immunohistochemical results, an image analysis was conducted using the Image Pro Plus (Media cybernetics, USA). The data was presented as the mean \pm standard error. The skin slices that were randomly selected from each group imaged at $\times 400$ magnification and analyzed with positive pixels/10,000,000 pixels. The data of statistics were conducted with SPSS software (SPSS 23 , SPSS Inc., USA). The significance $(p<0.05)$ was verified by using one-way Analysis of Variance (ANOVA) and post-test was performed with Duncan's multiple range test.

\section{Results}

\section{Western blot analysis}

To confirm the effect of Douchi extracts on the formation of skin lipid barrier, the expression of protein such as involucrin and loricrin was measured by Western blot. Involucrin and loricrin are proteins secreted during the promotion of keratinocyte differentiation. The expression of Involucrin and loricrin was increased when keratinocyte differentiation begins, and the proteins that cross-linked by transglutaminase formed the cornified envelope protein that acts as physical barrier of skin. In particular, involucrin is forms a covalent bond with $\omega$-hydroxyceramide in the stratum corneum, thereby forming a complete skin barrier structure with a combination of lipid membrane and the cornified envelope protein ${ }^{23)}$.

It was treated with 50,100 , and $200 \mu \mathrm{g} / \mathrm{ml}$ of Douchi extracts in western blot. As a result, the expression level of involucrin and loricrin increased at $200 \mathrm{\mu g} / \mathrm{ml}$ concentration (Fig. 2).

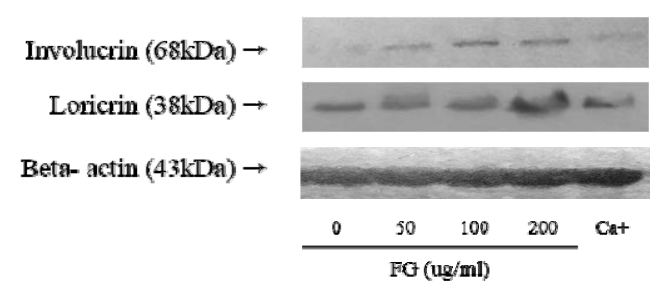

Fig. 2. Activation of involucrin and loricrin production by extract of fermameted Glycine max Merr.

\section{Positive-reaction of Loricrin}

Loricrin-positive reaction in the stratum corneum was $46,742 \pm 687 / 10,000,000$ pixel in $5 \mathrm{~W}$-Ctrl group, which was $108.0 \%$ higher that of $3 \mathrm{~W}-\mathrm{Ctrl}$ group. Whereas, in the 5W-FGT group, it was observed $71,844 \pm 481 / 10,000,000$ pixels, which is $54 \%$ higher than the 5W-Ctrl group (Fig. 3). 


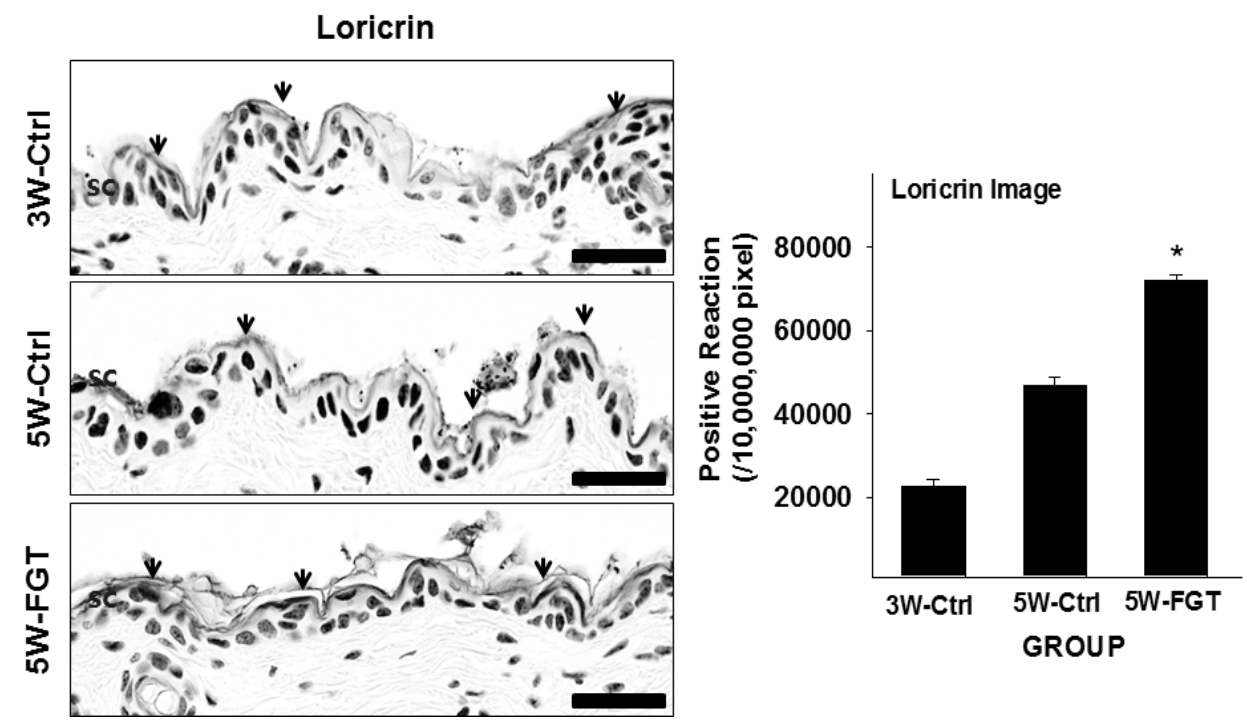

Fig. 3. Activation of loricrin production by extract of fermameted G/ycine max Merr. The loricrin positive reaction(arrows indicate) increased in SC of the 5W-FGT group compared with the 5W-Ctrl group (Loricrin immunohistochemistry; Bar size, $50 \mu \mathrm{m})$. Data of loricrin image analysis was also shown same result ( $p<0.05)$. Abbreviations. SC, stratum corneum; 3W-Ctrl, no treated 3th week ages; 5W-Ctrl, no treated 5th week ages; 5W-FGT, fermameted Glycine max Merr. of Hatedock treated 5 th week ages; ${ }^{*} \not<0.05$, compared with the $5 \mathrm{~W}-\mathrm{Ctrl}$.

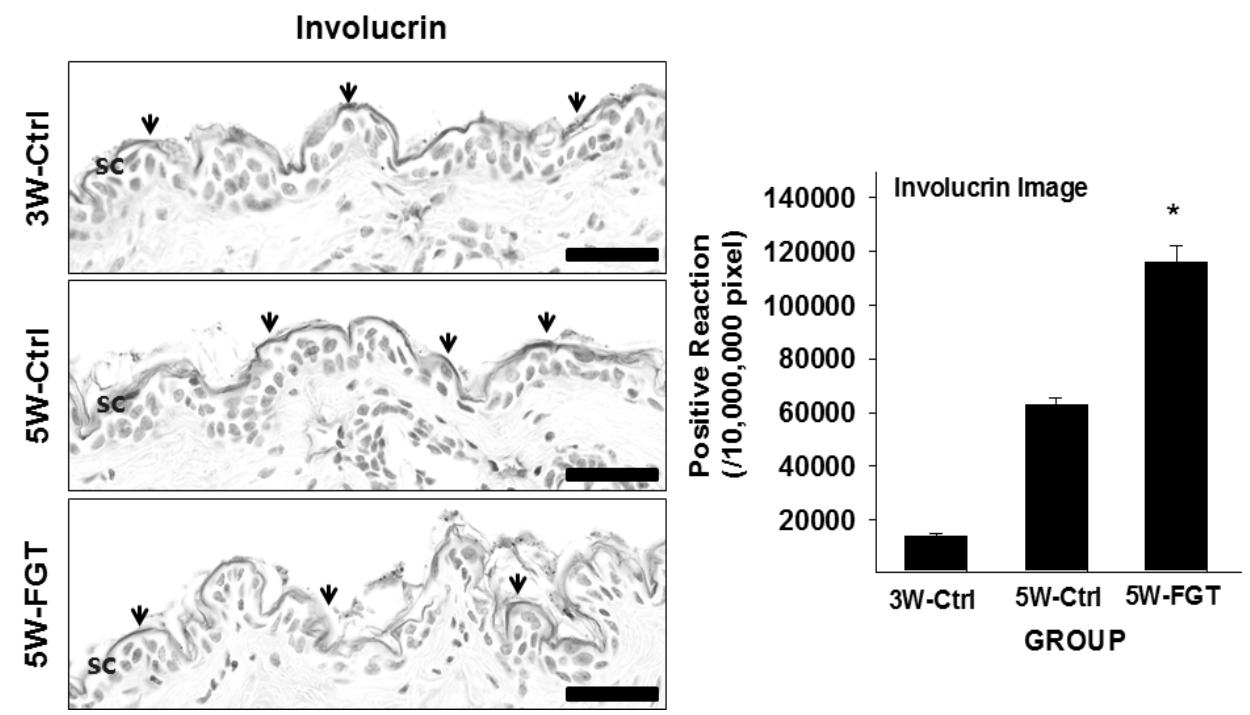

Fig. 4. Activation of involucrin production by extract of fermameted Glycine max Merr. The involucrin positive reaction(arrows indicate) increased in SC of the 5W-FGT group compared with the 5W-Ctrl group(involucrin immunohistochemistry; Bar size, $50 \mu \mathrm{m})$. Data of involucrin image analysis was also shown same result $(\not<0.05)$. Abbreviations same as Fig. 3. 
higher than the 5W-Ctrl group (Fig. 5).

\section{Positive-reaction of ASM}

ASM-positive reaction in the stratum corneum was $55,246 \pm 585 / 10,000,000$ pixel in 5W-Ctrl group, which was $117 \%$ higher that of $3 \mathrm{~W}-\mathrm{Ctrl}$ group.

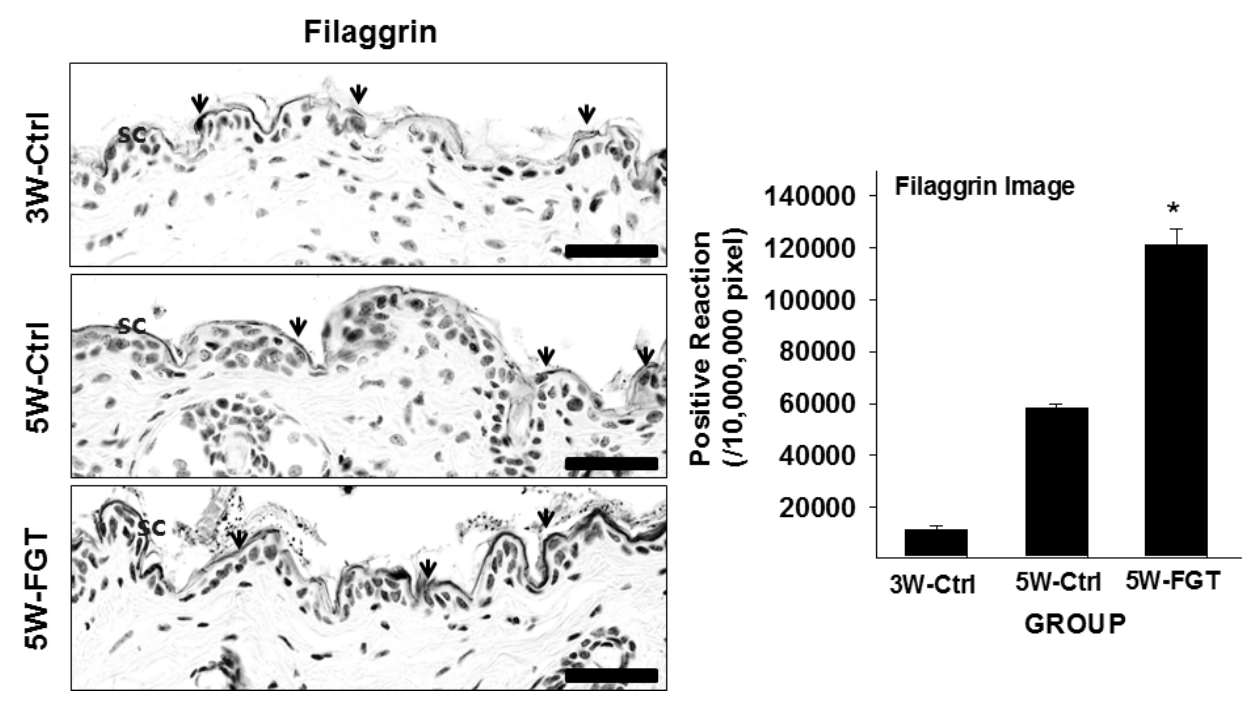

Fig. 5. Activation of Filaggrin production by extract of fermameted Glycine max Merr. The filaggrin positive reaction(arrows indicate) increased in SC of the 5W-FGT group compared with the 5W-Ctrl group(Filaggrin immunohistochemistry; Bar size, $50 \mu \mathrm{m})$. Data of filaggrin image analysis was also shown same result $(\not\langle 0.05)$. Abbreviations same as Fig. 3.

\section{Positive-reaction of Involucrin}

Involucrin-positive reaction in the stratum corneum was $63,117 \pm 760 / 10,000,000$ pixel in $5 \mathrm{~W}$-Ctrl group, which was $1358 \%$ higher that of $3 \mathrm{~W}-\mathrm{Ctrl}$ group. Whereas, in the 5W-FGT group, it was observed $116,130 \pm 1,829 / 10,000,000$ pixel, which is $84 \%$ higher than the $5 \mathrm{~W}$-Ctrl group (Fig. 4).

\section{Positive-reaction of Filaggrin}

Filaggrin-positive reaction in the stratum corneum was $58,138 \pm 522 / 10,000,000$ pixel in $5 \mathrm{~W}$-Ctrl group, which was $411 \%$ higher that of $3 \mathrm{~W}-\mathrm{Ctrl}$ group. Whereas, in the $5 \mathrm{~W}$-FGT group, it was observed $120,876 \pm 2,084 / 10,000,000$ pixel, which is $108 \%$
Whereas, in the 5W-FGT group, it was observed $105,261 \pm 1,567 / 10,000,000$ pixel, which is $91 \%$ higher than the $5 \mathrm{~W}-\mathrm{Ctrl}$ group (Fig. 6).

\section{Toxicity of the Douchi}

In previous studies using the Douchi extracts, we confirmed the safety for toxicity in $\mathrm{NC} / \mathrm{Nga}$ mice ${ }^{50}$, and based on these results, we administered with 10 $\mathrm{mg} / \mathrm{kg}$ of Douchi orally. No significant toxicity was reported in cells or animals treated with soybean -related products and the Douchi was reported to be toxic at high doses of $2.5 \mathrm{~g} / \mathrm{kg} /$ day $^{51)}$. 


\section{Discussion}

The most important function of the skin is a role as a skin barrier that keeps moisture and prevents the penetration of pathogens and infectious substances ${ }^{19)}$. Recently, studies on the relationship between skin diseases and skin barrier function have been reported $^{20,21)}$, and the development of therapeutic and free fatty acids in stratum corneum play an important role in skin barrier and keeping moisture $^{25)}$.

The ceramide is a representative keeping moisture substance $^{26)}$, particularly, it has been reported that reduced expression in skin of atopic dermatitis ${ }^{27)}$. The causes of decrease in ceramide are increased metabolism, abnormality of synthesis, and excessive
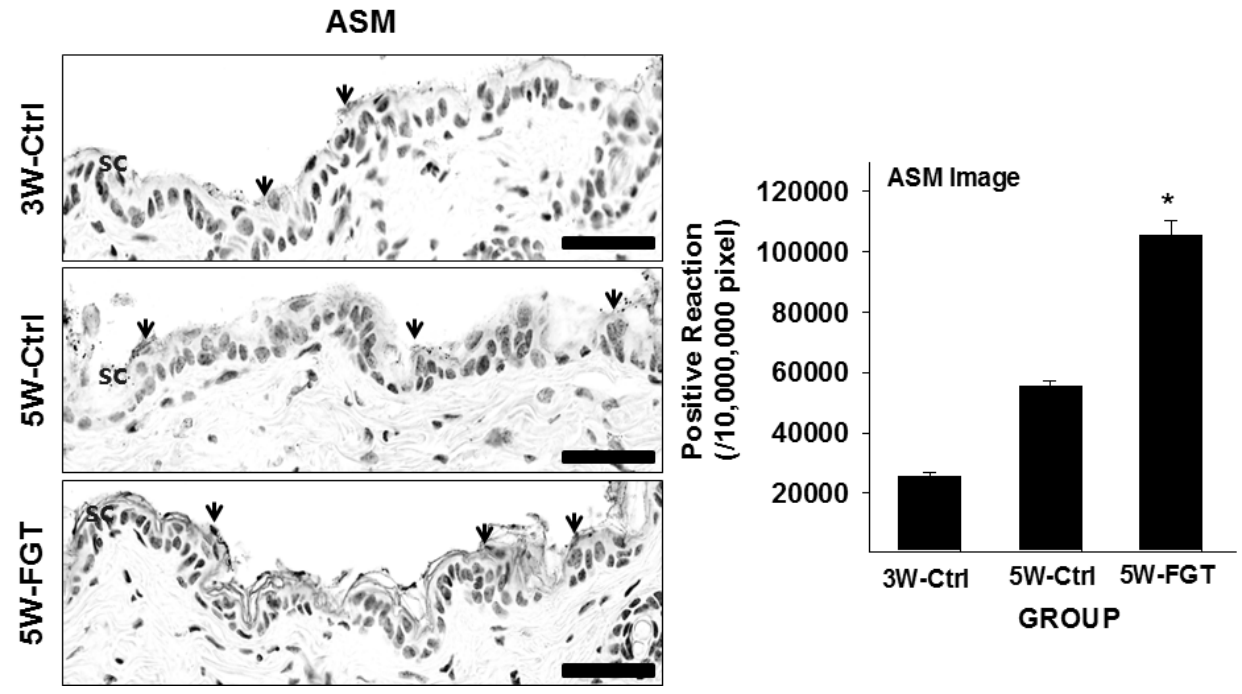

Fig. 6. Activation of ASM production by extract of fermameted Glycine max Merr. The ASM positive reaction(arrows indicate) increased in SC of the 5W-FGT group compared with the 5W-Ctrl group(ASM immunohistochemistry; Bar size, $50 \mu \mathrm{m})$. Data of ASM image analysis was also shown same result ( $\not<0.05)$. Abbreviations same as Fig 3.

agents for skin diseases to enhance the functions of skin barrier and moisture retention has been proceeding consistently ${ }^{22}$.

The epidermis is mainly in charge of skin barrier function $^{23)}$. The keratinocytes in the basal layer of the epidermis are differentiated by migration to the upper layer after divisions, and these changes of epidermis are caused by the expression of the gene regulated by this process. The genes that promoting the expression are transglutaminaes 1 and 3, involucrin, loricrin, cornifin, filaggrin, and small proline-rich protein $(\mathrm{SPR})^{24)}$.

The interstitial lipids including ceramide, cholesterol decomposition $^{28)}$.

The free fatty acid is substances that maintain the mild acidity of $\mathrm{pH} 4.5-5.5$ at epidermis and contribute to the maintenance of the homeostasis of the skin barrier ${ }^{29)}$, and it has been formed by metabolizing phospholipids with secretory phospholipase A2 (sPLA2) $)^{30}$. Acidic $\mathrm{pH}$ is important role in maintaining homeostasis of skin barrier. After skin damages, it has been normal skin barrier recovery process at acidic $\mathrm{pH}$. However, when $\mathrm{pH}$ is increased, recovery process is delayed and firmness of the stratum corneum is reduced by accelerating decomposition of corneodesmosome and activity of 
serine protease. It also lead to decrease function of $\beta$ -glucocerebrosidase and ASM, thereby reducing the production of ceramides ${ }^{31)}$.

The keratinocytes are a final products of skin differentiation process and continuously replaced with keratinocytes that have undergone a new differentiation process. In these process, the proteolytic enzyme involved in the elimination of keratinocytes are also controlled by the $\mathrm{pH}$ of the stratum corneum ${ }^{32,33)}$. If the $\mathrm{pH}$ of the skin surface increases, the activity of serine protease increases. It causes an abnormal skin barrier function through promotes the elimination of keratinocytes resulting from the abnormal decomposition of the keratinocyte component ${ }^{31,34-35)}$. In atopic dermatitis, the skin is not perform normal skin barrier functions because of the higher $\mathrm{pH}$ of the skin lesions than that of non-lesion $^{36}$.

In aging skin, the most important characteristic of the cholesterol is a synthetic disorder that reported to be associated with decreased skin barrier function ${ }^{37}$.

In this study, we identify that effect of skin lipid barrier formation on Hataedock treatment with Douchi based on previous studies such as control on atopic dermatitis, maintenance of skin stratum corneum, reduction of PKC activity and reduction of epidermal cell hyperplasia.

Involucrin is one of the differentiation promoting factors of keratinocyte. It is a soluble protein with a -helix structure and the first described protein as a precursor protein that constitutes the cornified cell envelope. It is concentrated at the outermost part of the keratinocytes, is used as a marker of epidermal differentiation, and serves as a scaffold in process of cross-linking several precursor proteins ${ }^{38)}$.

Loricrin expressed in the granular layer is the main protein that constitutes cornified cell envelope and accounts for $70-85 \%$ of total protein weight. The cross-linking of loricrin-loricrin, and loricrin-SPRs are play a role as strengthening cornified cell envelope ${ }^{38)}$.
Involucrin and loricrin are known to be important proteins in epidermal differentiation and skin barrier formation $^{23)}$. In the case of atopic dermatitis, it is confirmed that involucrin and loricrin was significantly reduced because the IL-4 and IL13 induced by the over-expressed Th2 cytokines are activating the STAT-6 signal pathway ${ }^{39)}$.

Filaggrin acts as a matrix protein that aggregates keratins. It is decomposed into free amino acids by various enzymes to bind to water, thereby acting as a natural moisturizing factor. Also it has functions that regulation of $\mathrm{pH}$ and filter of $\mathrm{UV}^{40,}{ }^{41}$. It is reported that filaggrin mutation leads to skin inflammatory reaction caused skin barrier damage in atopic dermatitis and facilitated Ig E sensitization through the damaged skin barrier. So filaggrin is typically considered to be a genetic factor of atopic dermatitis $^{42)}$.

ASM is an enzyme that converts sphingomyelin to ceramide. It plays a major role in the development of skin barrier. It is reported that the deficiency of ASM in atopic dermatitis causes impairment of recovery after skin barrier damage ${ }^{43)}$ and the reduced activity of ASM in atopic dermatitis leads to skin barrier disorders through reducing the ceramide, involucrin, loricrin, and filaggrin ${ }^{44)}$.

Traditionally, the hypothesis on the mechanism of atopic dermatitis is the inflammation of skin associated with the Type 2 immune response was predominant. Recently, it has been understood as a concept called "outside to inside", which is the results of the skin barrier dysfunction due to the permeability of the epidermis and damage on the antibacterial barrier function ${ }^{45}$. However, an outside-inside-outside hypothesis has been suggested that inflammation of the skin caused by the immunological mechanism causes skin barrier damage again. It is reported that the skin barrier damage of atopic dermatitis induces type 2 cytokine-mediated inflammatory responses, and that induced inflammation again damages the skin 
barrier ${ }^{46)}$. Through these studies results, renewed understanding of skin barrier abnormalities and immunological abnormalities.

Actually, it is known that Th2 cytokine reduces directly the recovery rate after skin barrier damage and suppresses the expression of filaggrin, loricrin and involucrin, which are the main components of differentiated keratinocytes. Also it suppresses the expression of antimicrobial peptide in charge of synthesizing ceramides and inherent immunity ${ }^{47-49)}$.

Therefore, in this study to confirm the induction effect of the lipid barrier formation Hataedock treatment with Douchi, we measured the Western blot to observe the expression of involucrin and loricrin as components of the cornified protein envelope and also observed the positive-reaction of involucrin, loricrin, filaggrin and ASM in the stratum corneum.

As a result, it was treated with 50, 100, and 200 $\mu \mathrm{g} / \mathrm{ml}$ of Douchi extracts in western blot, the expression level of involucrin and loricrin is increased at concentration of $200 \mu \mathrm{g} / \mathrm{ml}$. In addition, the positive-reaction of involucrin, loricrin, filaggrin and ASM in the stratum corneum after Douchi treatment was significantly increased. These findings suggest that the Hataedock treatment with Douchi improved and enhanced the skin lipid barrier by the promoting differentiation of keratinocytes. Our results considered that Hataedock treatment with Douchi induces the skin barrier formation through formation and maintenance of the cornified cell envelope by increasing the expression of proteins promoted when differentiation of keratinocytes. Further studies are necessary to investigate the mechanism of keratinocytes differentiation and verify the efficacy of the Hataedock treatment.

\section{Conclusion}

In this study, to investigate the effect of skin lipid barrier formation on Hataedock with Douchi, the following results were obtained by observing immunohistochemical changes in dorsal skin of NC/Nga mice.

1. The expression of Involucrin and loricrin was increased in the Western blot that was treated with concentration of Douchi extracts.

2. Positive reaction of involucrin, loricrin, filaggrin and ASM in the stratum corneum were significantly increased in the Hataedock treatment with Douchi group $(p<0.05)$.

\section{Acknowledgement}

This study was supported by the Basic Science Research program through the National Research Foundation of Korea (NRF) funded by the Ministry of Education (No. NRF-2016R1D1A1B03930474).

\section{References}

1. Kim YJ, Ahn JY, Seo SJ, Hong CK. The effect of retinoic acid on expression of human beta defensin-2 and LL-37 in keratinocyte. J Korean Invest Dermatol. 2007;14:29-35.

2. Kwon MS, Choi TB, Kim GY. The Effect on the Skin Barrier Function of Ceramide. Kor J Aesthet Cosmetol. 2005;3(1):131-7.

3. Yoon YM, Yoon JY, Lim KM, Hahn HJ, Kim YR, Ahn KJ, et al. Effects of the complex containing Centella asiatica-and folic acid-fermented extracts, acetyl glutamine, and nicotinic acid adenine dinucleotide phosphate on the inhibition of senescence and elanogenesis, promotion of collagen expression, cellular regeneration, and keratinocyte differentiation, and anti-inflammation. Kor J Aesthet Cosmetol. 2013;11:675-84.

4. Steinert PM, Marekov LN. The proteins elafin, filaggrin, keratin intermediate filaments, loricrin, and small proline-rich proteins 1 and 2 are isodipeptide cross-linked components of the human epidermal cornified cell envelope. J Biol 
Chem. 1995;270:17702-11.

5. Steven AC, Steinert PM. Protein composition of cornified cell envelopes of epidermal keratinocytes. J Cell Sci. 1994;107(2):693-700.

6. Elias PM, Menon GK. Structural and lipid biochemical correlates of the epidermal permeability barrier. Adv Lipid Res. 1991;24:1-26.

7. Steinert PM, Cantieri JS, Teller DC, Lonsdale -Eccles JD, Dale BA. Characterization of a class of cationic proteins that specifically interact with intermediate filaments. Proc Natl Acad Sci USA. 1981;78:4097-101.

8. Cornelissen C, Marquardt Y, Czaja K, Wenzel J, Frank J, Luscher-Firzlaff J, et al. IL-31 regulates differentiation and filaggrin expression in human organotypic skin models. J Allergy Clin Immunol. 2012;129:426-33.

9. Irvine $\mathrm{AD}$, McLean WH. Breaking the (un)sound barrier: filaggrin is a major gene for atopic dermatitis. J Invest Dermatol. 2006;126:1200-02.

10. Palmer $\mathrm{CN}$, Irvine $\mathrm{AD}$, Terron-Kwiatkowski $\mathrm{A}$, Zhao Y, Liao H, Lee SP, et al. Common loss-of-function variants of the epidermal barrier protein filaggrin are a major predisposing factor for atopic dermatitis. Nat Genet. 2006;38:441-6.

11. O'Regan GM, Irvine AD. The role of filaggrin in the atopic diathesis. Clin Exp Allergy. 2010; 40:965-72.

12. Barnes KC. An update on the genetics of atopic dermatitis: scratching the surface in 2009. J Allergy Clin Immunol. 2010;125(1):16-29.

13. Kim BB, Kim JR, Kim JH, Kim YA, Park JS, Yeom $\mathrm{MH}$, et al. 7, 3', 4'-Trihydroxyisoflavone ameliorates the development of Dermatophagoides farinae-induced Atopic Dermatitis in NC/Nga Mice. Evid Based Complement Alternat Med. 2013;2013:636597.

14. Kang MY, Jang GT, Kim JH. A study on fetal toxicosis removal therapy. J Pediatr Korean Med. 2003;17(1):9-51.

15. Heo J. DongUiBoGam. 2nd ed. Seoul:NamSanDang.
2004.

16. Miller AK, Benson JM, Muanza DN, Smith JR, Shepherd DM. Anti-inflammatory effects of natural product formulations on murine dendritic cells. J Diet Suppl. 2011;8(1):19-33.

17. Yeh CY, Jung CJ, Huang CN, Huang YC, Lien HT, Wang WB, et al. A legume product fermented by Saccharomyces cerevisiae modulates cutaneous atopic dermatitis-like inflammation in mice. BMC Complement Altern Med. 2014;14: 194-201.

18. Song JH, Ahn SH, Chen JH, Park SY, Kim HH, Kim KB. Effects of Hataedock with Douchi on 2, 4-dinitrofluorobenzene-induced Atopic Dermatitis-like Skin Lesion in NC/Nga Mice. J Physiol \& Pathol Korean Med. 2016;30(2): 109-15.

19. Forslin B. A domain mosaic model of the skin barrier. Acta Derrn Venereol. 1994;74(1):1-6.

20. Mohsenzadeh M. Evaluation of antibacterial activity of selected Iranian essential oils against Staphylococcus aureus and Escherichia coli in nutrient broth medium. Pak J Biol Sci. 2007; 10(20):3693-97.

21. Rasul A, Akhtar N, Khan BA, Mahmood T, Uz ZS, Khan HM. Formulation development of a cream containing fennel extract: in vivo evaluation for anti-aging effects. Pharmazie. 2012;67(1);54-8.

22. Yu HY, Yang IJ, Lincha VR, Park IS, Lee DU, Shin HM. The Effects of the Fruits of Foeniculum vulgare on Skin Barrier Function and Hyaluronic Acid Production in $\mathrm{HaCaT}$ Keratinocytes. J Life Sci. 2015;25(8):880-8.

23. Steinert PM, Marekov LN. The proteins elafin, filaggrin, keratin intermediate filaments, loricrin, and small proline-rich proteins 1 and 2 are isodipeptide cross-linked components of the human epidermal cornified cell envelope. J Biol Chem. 1995;270(30):17702-11.

24. Kwon YB, Choi DK, Sohn KC, Jeon EK, Nam 
MS, Lee JH, et al. Effects of Colostrum on Keratinocyte Differentiation and Wound Healing, Kor J Invest Dermatol. 2007;14(2):45-50.

25. Imokawa $\mathrm{G}$, Abe A, Jin $\mathrm{K}$, Higaki $\mathrm{Y}$, Kawashima M, Hidano A. Decreased level of ceramides in stratum corneum of atopic dermatitis: An etiologic factor in atopic dry skin? Kor J Invest Dermatol. 1991;96(4):523-6.

26. Choi MJ, Maibach HI. Role of ceramides in barrier function of healthy and diseased skin. Am J Clin Dermatol. 2005;6:215-23.

27. Hara J, Higuchi K, Okamoto R, Kawashima M, Imokawa G. High-expression of sphingomyelin deacylase is an important determinant of ceramide deficiency leading to barrier disruption in atopic dermatitis. J Invest Dermatol. 2000; 115:406-13.

28. Murata Y, Ogata J, Higaki Y, Kawashima M, Yada Y, Higuchi K, et al. Abnormal expression of sphingomyelin acylase in atopic dermatitis: an etiologic factor for ceramide deficiency?. J Invest Dermatol. 1996;106:1242-9.

29. Proksch E, Brandner JM, Jensen JM. The skin: an indispensable barrier. Exp Dermatol. 2008; 17:1063-72.

30. Fluhr JW, Kao J, Jain M, Ahn SK, Feingold KR, Elias PM. Generation of free fatty acids from phospholipids regulates stratum corneum acidification and integrity. J Invest Dermatol. 2001;117:44-51.

31. Hachem JP, Crumrine D, Fluhr J, Brown BE, Feingold KR, Elias PM. Ph directly regulates epidermal permeability barrier homeostasis, and stratum corneum integrity/cohesion. J Invest Dermatol. 2003;121:345-53.

32. Proksch E, Brandner JM, Jensen JM. The skin: an indispensable barrier. Exp Dermatol. 2008; 17:1063-72.

33. Baroni A, Buommino E, De Gregorio V, Ruocco E, Ruocco V, Wolf R. Structure and function of the epidermis related to barrier properties. Clin Dermatol. 2012;30:257-362.

34. Hachem JP, Man MQ, Crumrine D, Uchida Y, Brown BE, Rogiers V, et al. Sustained serine proteases activity by prolonged increase in $\mathrm{pH}$ leads to degradation of lipid processing enzymes and profound alterations of barrier function and stratum corneum integrity. J Invest Dermatol. 2005;125:510-20.

35. Schmid-Wendtner MH, Korting HC. The $\mathrm{pH}$ of the skin surface and its impact on the barrier function. Skin Pharmacol Physiol. 2006;19: 296-302.

36. Rippke F, Schreiner V, Doering T, Maibach HI. Stratum corneum $\mathrm{pH}$ in atopic dermatitis: impact on skin barrier function and colonization with Staphylococcus Aureus. Am J Clin Dermatol. 2004;5:217-23.

37. Elias PM, Ghadially R. The aged epidermal permeability barrier: basis for functional abnormalities. Clin Geriatr Med. 2002;18: 103-20.

38. Steinert PM, Marekov LN. Direct evidence that involucrin is a major early isopeptide cross linked component of the keratinocyte cornified cell envelope. J BiolChem. 1997;272:2021-30.

39. Kim BE, Donald YML, Mark B, Michael DH. Loricrin and involucrin expression is down -regulated by Th2 cytokines through STAT-6. Clin Immunol. 2008;126:332-7.

40. Palmer CN, Irvine AD, Terron-Kwiatkowski A, Zhao Y, Liao H, Lee SP, et al. Common loss-of-function variants ofthe epidermal barrier protein filaggrin are amajor predisposing factor for atopic dermati-tis. Nat Genet. 2006;38:441-6.

41. Smith FJ, Irvine AD, Terron-Kwiatkowski A, Sandilands A, Campbell LE, Zhao Y, et al. Loss of function mutations in the geneencoding filaggrin cause ichthyosis vulgaris. Nat Genet. 2006;38:337-42.

42. O'Regan GM, Irvine AD. The role of filaggrin in the atopic diathesis. Clin Exp Allergy. 
2010;40:965-72.

43. Pullmannovaa P, Stankova K, Pospisilova M, Skolova B, Zbytovska J, Vavrova K. Effects of sphingomyelin/ceramide ratio on the permeability and microstructure of model stratum corneum lipid membranes. Biochim Biophys Acta Biomembr. 2014;1838(8):2115-26.

44. Jensen JM, Folster-Holst R, Baranowsky A, Schunck M, WinotoMorbach S, et al. Impaired sphigomyelinase activity and epidermal differentiation in atopic dermatitis. J Invest Dermatol. 2004;122:1423-31.

45. Elias PM, Schmuth M. Abnormal skin barrier in the etiopathogenesis of atopic dermatitis. Curr Opin Allergy Clin Immunol. 2009;9:437-46.

46. Elias PM, Steinhoff M. "Outside-to-Inside" (and Now Back to "Outside") Pathogenic Mechanisms in Atopic Dermatitis. J Invest Dermatol. 2008; 128(5):1067-70.

47. Hatano Y, Ter2ashi H, Arakawa S, Katagiri K. Interleukin-4 suppresses the enhancement of ceramide synthesis and cutaneous permeability barrier functions induced by tumor necrosis factor-alpha and interferon-gamma in human epidermis. J Invest Dermatol. 2005;124:786-92.

48. Kim BE, Leung DY, Boguniewicz M, Howell MD. Loricrin and involucrin expression is down -regulated by Th2 cytokines through STAT- 6 . Clin Immunol. 2008;126:332-7.

49. Albanesi C, Fairchild HR, Madonna S, Scarponi C, De Pita O, Leung DY, et al. IL-4 and IL-13 negatively regulate TNF-alpha- and IFN-gamma induced beta-defensin expression through STAT-6, suppressor of cytokine signaling (SOCS)-1, and SOCS-3. J Immunol. 2007;179: 984-92.

50. Jung AR, Ahn SH, Park IS, Park SY, Jeong SI, Cheon JH, et al. Douchi (fermented Glycine max Merr.) alleviates atopic dermatitis-like skin lesions in $\mathrm{NC} / \mathrm{Nga}$ mice by regulation of $\mathrm{PKC}$ and IL-4. BMC Complementary and Alternative Medicine. 2016;16(416)

51. Fujita H, Yamagami T. Absence of mutagenicity, genotoxicity, and subchronic oral toxicity of Touchi extract. Int J Toxicol. 2007;26(5):465-73. 